\title{
BALANÇO DE ENERGIA DURANTE UM CULTIVO DE TRIGO NO SUL DO BRASIL
}

\author{
Gisele Cristina Rubert ${ }^{1}$, Joel Rubert ${ }^{1}$, Débora Regina Roberti ${ }^{1}$ \\ ${ }^{1}$ Universidade Federal de Santa Maria/Santa Maria, RS - Brasil \\ e-mail: girubert@gmail.com
}

\begin{abstract}
Energy fluxes estimates in the form of sensible, latent, and soil heat fluxes were done using the eddy covariance technique with observed data in one micrometeorological tower during the spring wheat cultive, 2001 winter cycle, in an experimental area located at Cruz Alta RS, Brazil.
\end{abstract}

\section{INTRODUÇÃO}

$\mathrm{O}$ balanço de energia torna-se importante, pois ele permite dimensionar as trocas de massa e energia no sistema solo-planta-atmosfera, através do estudo da partição do saldo de radiação $(R n)$ nos processos que ocorrem na superfície (Ramirez et. al. 2010). Neste trabalho, as trocas de energia entre um cultivo de trigo e a atmosfera foram estimadas para quatro fases de desenvolvimento do trigo.

\section{METODOLOGIA}

O experimento foi conduzido na Cooperativa Central Gaúcha Ltda Tecnologia (CCGL-Tec), com coordenadas geográficas $\left(28^{\circ} 36^{\prime} \mathrm{S}, 53^{\circ} 40^{\prime} \mathrm{W}, 425 \mathrm{~m}\right.$ de altitude), localizada no município de Cruz Alta-RS. Os fluxos de energia foram estimados, utilizando a técnica eddy covariance (Kaimal e Finnigan,1994). A semeadura do trigo foi realizada em 14 de junho de 2011, utilizando o cultivar FUNDACEP 300, e a colheita ocorreu em 09 de novembro de 2011, fechando um ciclo de 149 dias. O balanço de energia na superfície, fundamentado no princípio de conservação da energia, pode ser representado pela transferência de energia na forma de calor para aquecer a atmosfera (sensível), condensação de vapor d'água ou evaporação de água da superfície e transpiração das plantas (latente) e pela transferência de energia por condução para aquecer o solo. Assim, o balanço de energia pode ser expresso como:

$$
R_{n}-G=H+L e
$$

sendo $R n$ é o saldo de radiação $\left(\mathrm{Wm}^{-2}\right), G$ é o fluxo de energia no solo $\left(\mathrm{Wm}^{-2}\right), H$ o fluxo de energia na forma de calor sensível $\left(\mathrm{Wm}^{-2}\right)$ e $L e$ o fluxo de energia na forma de calor latente $\left(\mathrm{Wm}^{-2}\right)$. Os estádios fenológicos do trigo foram definidos segundo a escala de Feekes e Large (Large, 1954), divididos nas fases de emergência, perfilhamento, elongamento e amadurecimento.

\section{RESULTADOS}

Os ciclos diários médios para as componentes do balanço de energia nas fases fenológicas de emergência, perfilhamento, elongamento e amadurecimento são mostrados na figura 1. Para as diferentes fases fenológicas analisadas percebe-se que o fluxo de energia na forma de calor latente (Le) é positivo para todos os ciclos. Porém, há diferenças significativas em seus valores, o que demonstra a fenologia atuando na variação de Le. No início da cultura, com o solo nu, os valores médios de $\mathrm{H}$ e $\mathrm{G}$ são maiores. Com isso, há 
pouca energia sendo utilizada na evapotranspiração. Com o decorrer do cultivo, as plantas começam a cobrir o solo (índice de área foliar maior) e, consequentemente, a energia será utilizada, em maior parte, para a evapotranspiração. A tabela 1 mostra as médias para as componentes do balanço nas fases analisadas.

\section{CONCLUSÃO}

Em média, a energia disponível foi utilizada para evapotranspiração em todas as fases fenológicas analisadas. Nas fases de perfilhamento e elongamento, o fluxo de energia no solo foi negativo, o que significa que o subsolo aqueceu a superfície.

5. AGRADECIMENTOS: Os autores agradecem ao CNPq e a CAPES.

\section{REFERÊNCIAS BIBLIOGRÁFICAS}

LARGE, E. C. Growth stages in cereals. Plant Pathology, London, v. 3, p.128-129, 1954.

KAIMAL, J. C.; FINNIGAN, J. J. Atmospheric Boundary Layer Flows - Their Structure and Measurement. New York, Oxford University Press, p. 234-240, 1994.

RAMIREZ, G. H.; HATFIELD, J. L.; PRUEGER, J. H.; SAUER, T. J. Energy balance and turbulent flux partitioning in a corn-soybean rotation in the Midwestern US. Theoretical and Applied Climatolology, v. 100, p. 79-92, 2010.
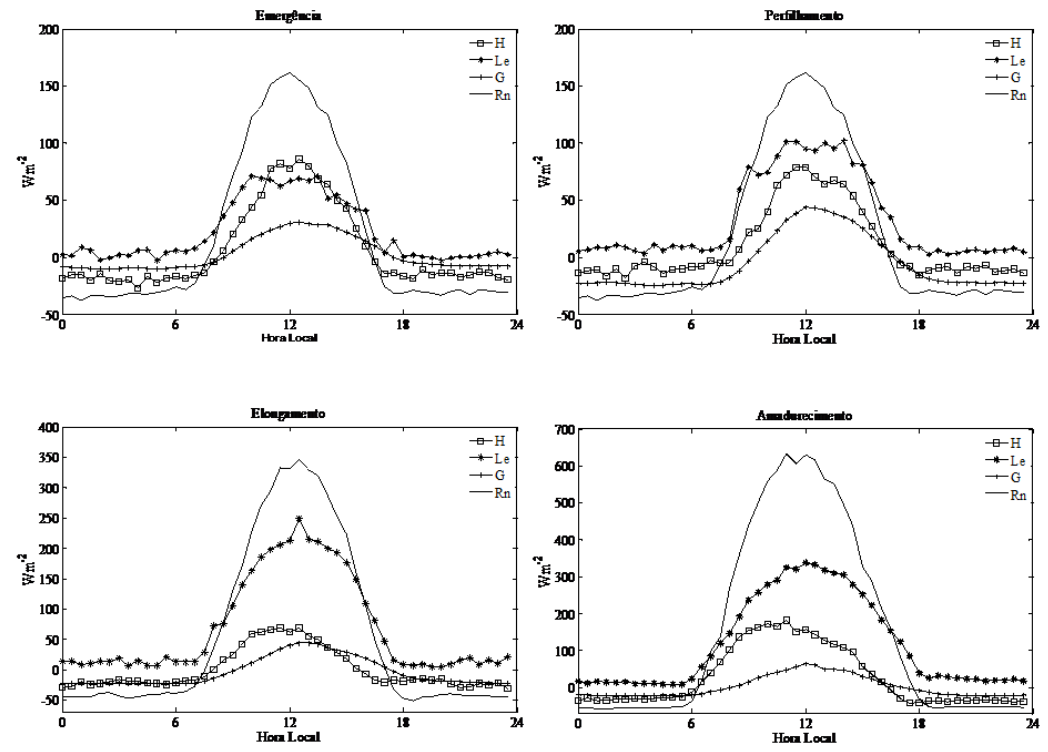

Figura 1: Ciclo diário médio para as componentes do balanço de energia $H$, Le, G e Rn durantes as fases fenológicas de cultivo de trigo em Cruz Alta- RS. 
Tabela 1 - Médias do ciclo diário das componentes do balanço de energia para os estádios fenológicos do Trigo. A primeira coluna mostra as fases fenológicas e a duração em dias desta fase.

\begin{tabular}{ccccc}
\hline Fases Fenológicas & $\begin{array}{c}H \\
\left(\mathrm{Wm}^{-2}\right)\end{array}$ & $\begin{array}{c}L e \\
\left(\mathrm{Wm}^{-2}\right)\end{array}$ & $\begin{array}{c}G \\
\left(\mathrm{Wm}^{-2}\right)\end{array}$ & $\begin{array}{c}R n \\
\left(\mathrm{Wm}^{-2}\right)\end{array}$ \\
\hline $\begin{array}{c}\text { Emergência } \\
(10 \text { dias })\end{array}$ & 6.41 & 22.29 & 2.46 & 17.94 \\
$\begin{array}{c}\text { Perfilhamento } \\
(48 \text { dias })\end{array}$ & 10.03 & 33.55 & -5.50 & 32.57 \\
$\begin{array}{c}\text { Elongamento } \\
\quad(23 \text { dias })\end{array}$ & 0.20 & 70.17 & -3.65 & 58.08 \\
$\begin{array}{c}\text { Amadurecimento } \\
\text { (23 dias) }\end{array}$ & 27.93 & 119.11 & 2.01 & 152.25 \\
\hline
\end{tabular}

